\title{
Gubernamentalidad, territorio y biopoder en los '30: El Anuario Rural de la Provincia de Buenos Aires
}

\author{
Governmentality, territory and bio-power in the 30: The Anuario Rural of \\ Buenos Aires province \\ Governabilidade, território e biopoder nos anos 1930: 0 Anuário Rural da \\ Província de Buenos Aires
}

Luis Ernesto Blacha*

Emmanuel Cicirello*

\section{Resumem}

El proceso histórico 1930-1946 en la Argentina se caracteriza por la ampliación intervencionista del Estado, producto del crac neoyorquino de 1929, que pone fin al paradigma del crecimiento hacia afuera. Es un contexto de importantes transformaciones donde el intervencionismo se combina con el fraude electoral para dar lugar a un estricto control social, sin renunciar al país agropecuario. Las políticas públicas implementadas interpelan a los ciudadanos como productores y el intervencionismo adquiere un carácter transformador de las prácticas productivas y del medioambiente. El análisis del Anuario Rural de la Provincia de Buenos Aires, difundido por el Ministerio de Obras Públicas, per- mite comprender el proceso del Estado intervencionista, como expresión de la ampliación del Estado en sus aspectos técnicos y burocráticos

Palabras clave: Estado. Territorio. Poder.
Doctor en Ciencias Sociales (Universidad de Buenos Aires). Investigador de CONICET y Centro de Estudios de la Argentina Rural, Universidad Nacional de Quilmes, Argentina. E-mail: luisblacha@gmail.com

*** Profesor de Historia. Becario de docencia e investigación en Centro de Estudios de la Argentina Rural, Universidad Nacional de Quilmes, Argentina. E-mail: emmanuelcicirello@gmail.com

Recebido em 12/02/2016 - Aprovado em 18/03/2016 http://dx.doi.org/10.5335/hdtv.16n.1.6252 


\section{Presentación}

El estudio de las estructuras administrativas supone una perspectiva interdisciplinar que refleje la complejidad del objeto de estudio. Son instituciones que canalizan los vínculos de poder, moldeando y sustentando las interacciones sociales y productivas. Los ciudadanos y el contexto ambiental están delimitados por las prácticas gubernamentales que se expresan en las políticas públicas. El Anuario Rural de la Provincia de Buenos Aires da cuenta de estas cuestiones - como publicación oficial referida al mundo rural - y focaliza en el vínculo entre los funcionarios expertos y los ciudadanos, entendidos como productores agropecuarios.

Los artículos que conforman el Anuario permiten reconstruir la importancia de la socialización al interior de las estructuras administrativas para difundir prácticas gubernamentales de forma coordinada. También dan cuenta de la interdependencia que se genera entre las estructuras administrativas y los ciudadanos que son objeto de las transformaciones propuestas. La publicación cobra nuevas significaciones en un contexto de democracia limitada, como es el de la Argentina durante los años `30. La ciudadanía política pareciera quedar relegada ante una "ciudadanía económica" enmarcada en el accionar de un Estado interventor. El objetivo es reconstruir los vínculos promovidos por esta publicación y contextualizarlos en el entramado social, político y económico donde la preocupación por la "productividad" interpela a los actores desde múltiples perfiles, para caracterizar la compleja producción rural de la provincia de Buenos Aires como eje de la economía agroexportadora argentina.
Los años '30: una década de

\section{transformaciones}

La década de 1930 en la Argentina se caracteriza por la ampliación intervencionista del Estado en un contexto donde los canales políticos formales de una democracia de masas se encuentran debilitados. El 'crac' neoyorquino de 1929, la ruptura del orden institucional con el golpe de Estado liderado por el general José Félix Uriburu y el fraude electoral para legitimar el gobierno desde 1932, se combinan con una crisis estructural que distancia a amplios sectores de la actividad política. Entre gobernantes y gobernados deben surgir nuevos ámbitos de vinculación y las políticas públicas cobran importancia como parte de estas transformaciones que inciden también en la producción agropecuaria pampeana.

Estos sectores gobernantes no logran adaptarse a las transformaciones que venían produciéndose en la sociedad argentina, en especial, aquellas modificaciones en la competencia electoral que promulga la Ley Sáenz Peña en 1912. El golpe de Estado de 1930 es interpretado por la clase política tradicional como el único medio para conseguir cambios de importancia, sustentado por la lógica de que "a grandes males, grandes remedios" (ROUQUIÉ, 1981, p. 186). Las diferencias al interior de la clase gobernante impactan sobre su organización porque se evitan los intermediarios políticos.

El general José Félix Uriburu promueve acciones "excepcionales" a través del golpe del 6 de septiembre de 1930. El gobierno provisional intenta reemplazar el dinamismo de la discusión política activa por la implemen- 
tación de un Estado corporativo, donde los políticos profesionales no tendrían cabida. Si la crisis económica es interpretada como una oportunidad para desplegar políticas de intervencionismo estatal, la ruptura institucional se vincula con la introducción de cambios en el ámbito político que no se condicen con las prácticas cívicas imperantes. El entramado social se convierte en problemático y deben ensayarse nuevas respuestas para administrar los conflictos, fuera del marco constitucional.

A diferencia de las propuestas reformistas del grupo uriburista, los oficiales del círculo del general Agustín P. Justo son hostiles a cualquier transformación autoritaria de las instituciones. Justo, el dirigente más hábil de la derecha argentina de entonces, propone la cooptación de nuevos integrantes al interior de su grupo para canalizar las interacciones políticas (MCGEE DEUTSCH, 2005). Los ámbitos administrativos conforman el escenario principal de este tipo de vínculos tutelados; donde la ética y el reglamento se imponen. Legitimarse y obtener consenso es el principal objetivo del Presidente Justo, que se respalda en los poderosos sectores agrarios.

La parálisis de la actividad política y la implementación del intervencionismo destacan la importancia de los cuadros intermedios (TCACH, 1991). Las nuevas funciones estatales requieren racionalidad, jerarquización y rapidez, que solo una estructura burocrática moderna puede consolidar. Este grupo intermedio de funcionarios y técnicos, también conforma un ámbito de socialización que refuerza la interdependencia entre gobernantes y gobernados mientras vincula el poder con el saber. Se constituye un ethos característico del profesionalismo administrativo que promueve nuevos fundamentos al orden social vinculados con el ascenso social basado en la capacitación y el desempeño institucional (DU GAY, 2012).

Las estructuras administrativas permiten vincular la organización social con las relaciones de poder y el estudio de sus publicaciones dan cuenta de la interdependencia gobernantes-gobernados. El Estado adquiere un papel destacado en la vida de los ciudadanos y ayuda a definir a una "población" mediante los conocimientos específicos que producen esas estructuras administrativas. A través de la burocracia, el poder amplía su alcance y su efectividad, conjugando el saber especializado, la organización, la técnica y la calculabilidad que caracterizan a las burocracias modernas y al ethos que rige el desempeño de sus funcionarios. El conocimiento que encierra la estructura administrativa es parte de la asimetría de los vínculos entre gobernantes y gobernados. Con las prácticas gubernamentales el conocimiento amplía sus áreas de intervención, influyendo en el sistema productivo bonaerense (FOUCAULT, 2007).

La consolidación del Estado interventor se expande con intensidad durante la presidencia del General Justo y su sucesor, Roberto Ortiz. El auxilio estatal permite superar los crecientes gastos de producción, los bajos precios cerealeros y aumentar la explotación intensiva (GIRBAL-BLACHA, 1998, p. 57). Durante la presidencia de Ortiz, continúan los trabajos "en el campo de Obras Públicas, en lo económico y social, del gobierno anterior" (AZARETTO, 1983, 
p. 109). No sólo se trata de políticas sociales, sino también en materia económica a través de las Juntas Reguladoras de la Producción y financieras mediante la reforma de la ley de Bancos (1935) y la creación del Control de Cambios (1931-1933) y el Banco Central de la República Argentina (1935) (GIRBAL-BLACHA, 1999, p. 1-16; ARNAUDO, 1987).

El conservador catamarqueño Ramón S. Castillo, es el Vicepresidente y sucesor del Presidente Roberto Ortiz luego de su muerte. Durante su presidencia se crea la Flota Mercante del Estado que intenta independizar parte del comercio exterior argentino. También se promueve el desarrollo minero con una activa exploración de yacimientos carboníferos y petrolíferos, para atenuar los problemas que trajo aparejada la Segunda Guerra Mundial. El Estado se convierte en un actor de gran importancia en el entramado social y su presencia en nuevos ámbitos se vincula con los avances del sector productivo.

En este contexto político, el crac del 29 tiene una influencia determinante porque supone una puesta en suspenso de la " $f e l i$ beral" de los miembros de la clase gobernante que les permite implementar el intervencionismo estatal. Además, refleja los límites del paradigma de crecimiento hacia afuera (GIRBAL-BLACHA; OSPITAL; ZARRILLI, 2005). Es una crisis estructural y orgánica que expresa una sintomatología social que altera la escala de valores vigentes (ahorro, propiedad, orden). Se realinea el mercado mundial, recobra fuerza el bilateralismo, las políticas deflacionistas persiguen la liquidación de stocks, los precios de los productos primarios se desploman, las quiebras se su- ceden, la desocupación se generaliza, se activa la polarización social y el Estado liberal entra en crisis. Se elevan los aranceles y se deprecia la moneda, estimulando la industrialización por sustitución de importaciones, como respuesta a la baja en el volumen de la exportación, la pérdida en los términos del intercambio y la cesación súbita de las entradas de capital (MADDISON, 1988, p. 30).

Las nuevas funciones estatales generan polémica en una sociedad que no está acostumbrada al intervencionismo. Tal es el caso, desde 1932, de las Juntas Reguladoras de la Producción (de carnes, de granos, de azúcar, de vinos, de algodón, de yerba mate) que están destinadas a subsidiar a la producción rural y agroindustrial que se conjugan con las distintas políticas públicas que proponen los Ministerios. El socialista independiente Federico Pinedo opina que la crisis:

[...] imponía al Estado la necesidad de tomar decisiones en terrenos antes ajenos a su área de competencia, no eliminaba del todo su libertad de acción en el momento de tomarlas (HALPERIN DONGHI, 1995, p. 148).

Los distintos actores interpretan su contexto de interacción como excepcional que se complementa con el patriotismo entendido como un valor en sí mismo.

La creación del Banco Central en 1935 es parte del Plan de Acción Económica como un intento para superar la crisis recurriendo al empapelamiento y la emisión (ARNAUDO, 1987, p. 15-33). También promueve un profesionalismo característico de estas estructuras administrativas racionales y modernas, que Paul Du Gay identifica con el 
ethos burocrático. Este ethos burocrático da cuenta de cómo las "instituciones estatales desempeñan labores fundamentales para que los ciudadanos que viven en democracia tengan una vida razonable" (2012, p. 20). Este ethos, como conjunto de prácticas, también incluye "restricciones burocráticas [que] son una condición esencial no sólo para evitar un comportamiento sectario, sino para garantizar la misma existencia en común" (2012, p. 30).

En la provincia de Buenos Aires, luego de la crisis en la gestión del gobernador y estanciero Federico Martínez de Hoz, los conservadores interpretan que sólo un fraude indisimulable les permitiría retener el poder. La actividad política provincial, pareciera quedar en el olvido con la implementación de estas tácticas. El conservador nacionalista Manuel Fresco, candidato a la gobernación, utiliza estas prácticas en su campaña electoral en 1935, entendiéndolas como una virtud e invoca la victoria revolucionaria de septiembre como fuente de legitimación para su gobierno (BÉJAR, 1986).

El Estado interventor procura dar respuesta a la crisis económica mundial y al fin del crecimiento externo del país. Las migraciones internas, del campo a la ciudad, marcan el fin de la expansión agropecuaria y plantea interrogantes sobre un modelo productivo donde las materias primas agrarias constituyen casi la totalidad de las exportaciones. El control social se convierte en uno de los fundamentos del poder. La centralidad del Estado en la vida pública adquiere nuevos significados que lo vinculan con un proceso histórico de la gubernamentalidad. En este sentido, puede afirmarse que:
[...] de resultar completamente insignificantes, los estados fueron de gran importancia en las vidas de los individuos a través de los recaudadores de impuestos y de los sargentos de reclutamiento. Despertaron a los individuos de su indiferencia histórica y política para exigir derechos representativos (MANN, 2006, p. 44).

La tensión entre las novedosas medidas de intervencionismo estatal y el sistema electoral fraudulento destacan el carácter cortoplacista de las políticas gubernamentales. Se intenta salvaguardar a los ciudadanos en sus necesidades básicas mientras se les quita el carácter político que los constituye en ciudadanos. El fraude reemplaza a la competencia electoral y paraliza la actividad política democrática. Si el período de victorias electorales radicales (1916-1928) (ROCK, 1977) puede ser caracterizado como de una preeminencia del político profesional, luego del golpe de Estado son los técnicos y burócratas quienes ocupan las posiciones destacadas en el Estado. El alcance geográfico de las decisiones políticas se amplía mientras se reducen quienes deciden (RAPOPORT, 2006).

En términos regionales, la provincia de Buenos Aires - eje de la economía agropecuaria - es un ejemplo esencial del proceso mencionado, que permite comprender las dinámicas novedosas de una elite que orienta a las políticas estatales hacia el intervencionismo en la economía, la política y la sociedad. Para alcanzar dicho objetivo, las prácticas tienen base en una burocracia técnica que es nexo entre los gobernantes y los actores sociales, sobre todo los pequeños productores, como factor fundamental para gestar un nuevo orden, bajo el "control social". 


\section{El Anuario de la Provincia de Buenos}

\section{Aires, expresión del intervencionismo estatal}

El Anuario Rural de la Provincia de Buenos Aires es una edición oficial, que difunde el Ministerio de Obras Públicas bonaerense. Su propuesta es interpelar a los pequeños productores para dar a conocer las políticas públicas implementadas. Los conceptos foucaultianos de gubernamentalidad, territorio y biopoder permiten interpretar a los actores que son objeto de la publicación desde su rol económico y como ciudadanos. Se estimula un abordaje del territorio como una construcción social, política y económica que actúa como un marco de certeza/ seguridad para la producción agropecuaria.

Esta publicación también puede interpretarse como parte de la socialización de los funcionarios que promueven las estructuras administrativas. Es posible incrementar tanto la intercambiabilidad de funciones como la interdependencia de los miembros de la clase gobernante para potenciar el alcance de sus decisiones. El ethos burocrático adquiere implicancias políticas y económicas que impactan en el entramado social. Lo interesante del objeto de estudio abordado es que el crecimiento de las estructuras administrativas se produce en un contexto donde las prácticas democráticas se encuentran limitadas.

La socialización prolongada en ciertos ámbitos es parte fundamento de la asimetría en las relaciones de poder. Las colaboraciones en los artículos del Anuario, reflejan esta sociabilidad compartida. El Estado se convierte:
[...] a la vez una entidad jurídica que garantiza los derechos y responsabilidades inscriptos en la Constitución y un conjunto de burocracias que respaldan el ejercicio de esa soberanía (HEREDIA, 2015, p. 228).

Estas garantías se vinculan con las prácticas políticas de las democracias de masas pero cobran nuevas implicancias en contextos de fraude electoral. La importancia de las instituciones públicas para promover la democracia está fundamentada en las:

[...] conversaciones generales que atraviesan las barreras de clase. La vida cívica requiere lugares en los que las personas se encuentren como iguales, sin tener en cuenta la raza, la clase o el origen nacional (LASCH, 1996, p. 105).

La difusión de una publicación oficial también permite dar cuenta que el Estado compite con otras instituciones para delimitar el entramado social. Las políticas públicas conviven con:

[...] las interacciones cargadas de conflictos de múltiples conjuntos de directrices, formales e informales, que establecen cómo actuar y que son promovidas por diferentes agrupaciones de la sociedad (MIGDAL, 2011, p. 27-28).

El entramado institucional no debe excluir el conflicto sino reconocerlo para administrarlo y moderarlo. Es éste uno de los objetivos del Anuario. Se propone un abordaje de la institucionalidad administrativa que lo pondere como ámbito de interacción y que dé cuenta del vínculo profundo que existe entre el poder y el saber, que permite al Estado abordar distintos ámbitos de la sociedad.

Las notas de los editores, bajo la Dirección de Agricultura, Ganadería e Industrias 
de Agustín Silvani Gómez1 y del ingeniero agrónomo César Ferri2 son un discurso oficial, que subraya los aspectos positivos de las políticas públicas implementadas. Hay una preocupación por reorganización las actividades productivas, que resultan en acciones concretas sobre el territorio. Si para Foucault el territorio refiere a "una noción jurídico-política" (CASTRO, 2004, p. 528), el objetivo del Anuario es determinar aquellos espacios que son controlados por el Estado. La utilización de las tierras que engloba a la Nación es un problema primordial para esta generación, para permitir al sistema productivo capitalista seguir desarrollándose sin cuestionar la primacía del rol exportador.

El estudio de las políticas públicas cobra importancia para registrar la interdependencia entre la consolidación de las estructuras centralizadas del Estado y la constitución del sujeto moderno. Las publicaciones oficiales son un medio destacado para reconstruir el pensamiento de los funcionarios que implementan estas prácticas gubernamentales. Los Estados-Nación "se desarrollaron y cambiaron a medida que interiorizaban las diferentes racionalidades parciales y contestadas del capitalismo, el militarismo y la representatividad" (MANN, 1997, p. 125). La consolidación de ciudadanos va más allá de sus derechos políticos, identificándose prácticas económicas que impactan sobre el territorio y el medio ambiente. Los discursos contenidos en el Anuario dan cuenta de esta preocupación, que supone una interpelación social del ámbito natural.

La internalización de las normas que fundamentan el orden social deben ser abordadas considerando la regulación discipli- nar de las conductas y de las necesidades individuales. La consolidación del aparato estatal politiza las características biológicas de los actores y se consolida una "economía" propia de las estructuras administrativas estatales. Los ámbitos de socialización potencian el alcance de estas prácticas, destacando las características arquitectónicas del poder para moldear el entorno. Los saberes contenidos en el Anuario promueven una resignificación de prácticas pero también de entornos para implementar una apropiación que incremente la productividad y permita una mejor inserción en el mercado mundial. No está ausente el control social en sus consejos técnicos.

La politización de las características biológicas de los ciudadanos y su entorno, resultan en un biopoder que debe ser entendido como:

[...] el conjunto de mecanismos por medio de los cuales aquello que, en la especie humana, constituye sus rasgos biológicos fundamentales podrá ser parte de una política, una estrategia política, una estrategia general de poder; en otras palabras, cómo, a partir del siglo XVIII, la sociedad, las sociedades occidentales modernas, tomaron en cuenta el hecho biológico fundamental de que el hombre constituye una especie humana (FOUCAULT, 2007, p. 15).

Es un poder sobre la vida que se fundamenta en las disciplinas del cuerpo. Una tecnología que individualiza al sujeto mientras lo inserta dentro de la especie humana como colectivo global. La diversidad caracteriza a la disciplina como un medio para la "individualización de las multiplicidades" (FOUCAULT, 2007, p. 28) que no concibe un "afuera" porque todos los individuos deben 
ser clasificados en el marco del control y disciplinamiento social.

Se identifica en el Anuario una orientación del Estado hacia la estabilidad del modelo agroexportador, canalizando y moldeando la diversidad. Se organizan las instituciones oficiales como los viveros "Eduardo L. Holmberg" de Cazón, que brinda productos forestales (plantas) para satisfacer e influir sobre las necesidades de los agricultores y ganaderos. El Director Agustín Silvani Gómez expresa:

[...] y a pesar de la diminución de los recursos durante el año, ello fue posible mediante un feliz reajuste de los servicios, y la mecanización de los trabajos, que redujo el costo de producción de las plantas (MOPPBA, 1940, p. 1).

Estas propuestas reflejan la preocupación de la clase gobernante para que las políticas públicas interpelen a los actores e implementen transformaciones que potencien la productividad de los distintos procesos del mundo rural.

Las transformaciones sobre el contexto medioambiental se producen en simultáneo con la interpelación de los ciudadanos que lo habitan. El trabajador rural es disciplinado, porque internaliza las normativas estatales que regulan sus acciones. Estos "nuevos" productores podrán reutilizar tierras para mejorar la efectividad de sus prácticas. En el surgimiento del capitalismo cobra gran importancia la resignificación de las "funciones" del poder, que "ya no apunta a reprimir sino a controlar y regular la vida y los movimientos de las poblaciones" (TRAVERSO, 2012, p. 217). Surgen entonces un conjunto de políticas públicas interdependientes que
Foucault identifica con la gubernamentalidad, es decir,

[...] el poder que se ejerce sobre la población concebida como un conjunto de procesos vitales, el poder que actúa como una técnica de regulación de los intercambios metabólicos entre el Estado y la sociedad (TRAVERSO, 2012, p. 217).

El Estado pretende a través del Anuario "actuar sobre uno o varios sujetos" (CASTRO, 2004, p. 235) para conducir y orientar las conductas humanas, interpelándolas con las transformaciones del territorio bonaerense en materia de turismo o actividades productivas. Por ejemplo, se hacen explícitos consejos en beneficio del sistema productivo:

Recomendamos particularmente a los hombres de nuestra campaña, a los propietarios de campo, fomenten las plantaciones de árboles forestales como de frutales, por los beneficios que dejan. En ninguna chacra debe faltar el monte, por los recursos que proporciona. Si se trata de forestales, dan sombra, abrigo contra los fríos, leña, varillas, postes, palos para lanza, balancines, etcétera (MOPPBA, 1938, p. 213).

Es posible reconstruir un recorrido histórico de estas prácticas que tienen como objeto la "vida" y que Michel Foucault identifica en la Europa del siglo XVIII. El cuerpo humano es interpretado como una máquina que puede ser intervenida a través de prácticas disciplinares. El cuerpo debe ser educado para aumentar sus capacidades, siendo más útil y más dócil. Es la anatomopolítica que vincula características biológicas con procesos económicos que tienen consecuencias políticas. La preocupación por la productividad se aborda a través de pequeñas 
secciones que pueden ser fácilmente controladas, reglamentadas y reguladas. Su expresión es la disciplina, el desgranamiento de un proceso amplio en secciones minúsculas. La disciplina individualiza en la multiplicidad porque:

[...] analiza, descompone a los individuos, los lugares, los tiempos, los gestos, los actos, las operaciones. Los descompone en elementos que son suficientes para percibirlos, por un lado, y modificarlos, por otro (FOUCAULT, 2007, p. 75).

Las editoriales del Anuario reconocen esta diversidad y promueven políticas para encausarla, delimitarla y moderarla para incrementar su productividad dentro de un sistema productivo de escala mundial. Las materias primas producidas se encuentran en interrelación con las necesidades del mercado mundial resultando en la resignificación de los ámbitos locales.

Las prácticas del Anuario pueden ser enmarcadas en la gubernamentalidad, porque:

[...] se ocupa de nuestra capacidad, cada día mayor, de controlar, administrar, modificar, redefinir y modular las propias capacidades vitales de los seres humanos en cuanto criaturas vivas. Es, como sugiero, una política de 'la vida en sí' (ROSE, 2012, p. 25).

La estadística, como ciencia del Estado, es la encargada de recabar la información que se convierte en insumo y fundamento de las políticas públicas (GONZÁLEZ BOLLO, 2014). El Anuario presenta la gran cantidad de información que recolecta el Estado provincial. La importancia de este conocimiento permite anticiparse a dificultades climáticas y contextuales que obstaculizarían el desarrollo del sistema productivo. Además, es posible construir un segundo nivel de reflexión que promueva un vínculo más cercano entre los productores y las estructuras administrativas. Este es el objetivo de las Editoriales del Anuario.

Las políticas públicas implementan un abordaje amplio y coordinado en diversas esferas. Desde 1938 hasta 1946 se presentan en el Anuario notas de los Directores de agricultura, ganadería e industrias, desarrollando políticas públicas y planificaciones futuras. Se muestra el plan de acción agrario (actividad realizada junto al Ministerio de Obras públicas), el cual se enmarca en las leyes provinciales 4416, 4417 y 4539 . Estas establecen aspectos referidos a la pesca, estaciones experimentales agronómicas y el Plan de Trabajos Públicos (fijación de médanos, arbolado y su mantenimiento en los caminos provinciales, creación de parques, ampliación del Mercado de Frutos de Tigre, fomento de las plantaciones forestales y de la agricultura y forestación de los bañados de la Ensenada de La Plata). Las instituciones oficiales utilizan la reglamentación que permite la ley y pone a trabajar al cuerpo de funcionarios técnicos para transformar el territorio en beneficio de un sistema productivo efectivo orientando las acciones desde el Anuario a través de recomendaciones de cómo proceder ante las enfermedades de plantas: 
Si usted observa sus plantas frutales, forestales $\mathrm{u}$ hortalizas atacadas por alguna enfermedad, remita, bien acondicionada, la parte enferma o atacada, sean hojas, ramas o frutos, a la Dirección General de Agricultura, Ganadería e Industrias, Pasaje Dardo Rocha, La Plata, que a vuelta del correo le será indicada la enfermedad y el tratamiento apropiado (MOPPBA, 1938, p. 304).

También intenta orientar las acciones del ciudadano en el campo turístico, a través del embellecimiento y urbanización de la costa atlántica: "Si usted es argentino debe visitar la ciudad balnearia de Mar del Plata y si es extranjero debe visitarla también con el objeto de compararla con las mejores playas del mundo" (MOPPBA, 1938, p. IX). El territorio es abordado como el ámbito para la cosecha de materia prima y también como el contexto que estimula las actividades recreativas. Es una interpelación de los sujetos como productores pero también como ciudadanos con derechos y deberes que es llamativo en un contexto de fraude electoral.

El doble abordaje que propone el Anuario, como productores y ciudadanos, es parte de las funciones que el poder oculta. El carácter omnipotente que Foucault atribuye al biopoder estatal se fundamenta en mediciones regulares y controles constantes de las acciones individuales (FOUCAULT, 2012). Estas prácticas adquieren mayor efectividad cuando se invisibilizan en controles internalizados. El poder debe "enmascarar una parte importante de sí mismo. Su éxito está en proporción directa con lo que logra esconder de sus mecanismos" (FOUCAULT, 1999, p. 105). La omnipresencia del poder es posible a costa de cierto ocultamiento porque "el poder está en todas partes; no es que lo englobe todo, sino que viene de todas partes" (FOUCAULT, 1999, p. 113).

El poder debe combinar la disciplina con los procesos de escala nacional para constituir la "seguridad" que se extiende por el territorio y complementa la idea arquitectónica que este tipo de vínculos tiene para Foucault. Mientras la disciplina restringe, la seguridad permite hacer a través de la interdependencia entre límites y libertad que promueve la modernidad. Las propuestas del Anuario vinculan prácticas disciplinares con la perspectiva de la seguridad. La burocracia moderna se convierte en un marco de referencia para las interacciones sociales porque guía la socialización que fundamenta el orden a través de la internalización de normas y pautas de comportamiento (ZABLUDOVSKY, 2007). El carácter práctico del poder circula en estos ámbitos administrativos estatales y amplía la importancia de esta institución en el entramado de relaciones sociales, donde el propio Estado interactúa con múltiples grupos que compiten por legitimar su autoridad (MIGDAL, 2011, p. 34).

Para lograr la expansión estatal en cuanto a gubernamentalidad, el Estado despliega trenes viveros para acercar las novedades a los trabajadores rurales, exposiciones, ferias para la venta de plantas, que proveen de condiciones favorables para obtener un mercado óptimo. A su vez, se produce el contacto entre los compradores y el plantador, relación que produce intercambio de conocimientos, orientaciones para perfeccionar las tareas rurales. Al Estado del período 1930-1946 le interesa primordialmente la "difusión de conocimientos que han de ir contribuyendo al perfeccionamien- 
to de los métodos de trabajo en la Provincia" (MOPPBA, 1940, p. 3-4). Si bien procura perfeccionar las tierras disponibles para la actividad agrícola mediante estudios sobre la degradación del suelo, no fue posible por las dificultades de la época. Para evitar la erosión del suelo - posible atenuante a obstaculizar la actividad productiva -, se intenta disponer de técnicos que estudien los perfiles y las novedades del territorio, lo cual requiere de recursos que no están disponibles.

En términos similares se aplica la Ley provincial 4416 que reglamenta la pesca e intenta proteger y acrecentar la riqueza lacustre. Los períodos de veda se combinan con restricciones en sistemas de pesca y tamaño de peces. Son prácticas estatales que permiten "la rápida educación del pescador profesional" (MOPPBA, 1940, p. 4). Desde los establecimientos de piscicultura se establecen programas para repoblar diversas lagunas estériles. Los técnicos implementan sus conocimientos:

[...] con el propósito de mejorar la explotación comercial de las lagunas, se construyó una calle de acceso a la Salada Grande, de General Madariaga, que permite llegar ahora por un camino público hasta la estación ferroviaria (MOPPBA, 1940, p. 5).

A pesar de la continua dificultad económica que atraviesa la Provincia de Buenos Aires en el período 1930 hasta la llegada del peronismo en 1946, la gestión del Estado procura que la "repartición" sea eficaz y organizada. Los ajustes constantes llevan a la supresión de personal técnico y son expresados en términos de "graves perturbaciones" en cuanto a los trabajos que se encuentran iniciados. La participación del sistema pro- ductivo en el mercado internacional se vuelve inestable por la Guerra Mundial y por las condiciones climáticas que deterioran las cosechas.

Para sortear la crisis producto de la baja de precios de los cereales y colocar los excedentes de producción en el mercado mundial, el Estado implementa políticas públicas para reducir el área cultivada y evitar errores, tales como destinar tierras que no son consideradas agrícolas para el cultivo del trigo:

[...] es necesario que los propietarios y agricultores, por propia iniciativa y en defensa de sus intereses, traten de consolidar prontamente los suelos alterados, forestándolos y alfalfándolos, a fin de no dar oportunidad a que en fecha próxima aparezca, extendido y reagravado el problema (MOPPBA, 1941, p. 2).

Desde el Estado se resignifican las prácticas para que los actores se adapten a las transformaciones de un contexto internacional cambiante. Prácticas que son posibles por la interdependencia poder-saber.

El vínculo con los productores se intensifica cuando la publicación del Anuario se combina con "el plan de difusión de conocimientos mediante la revista y el folleto" (MOPPBA, 1941, p. 4). También se divulgan programas radiales que tratan a cuestiones agrícolas. Un aspecto que demuestra la ampliación del conocimiento técnico ofrecido en diversos canales de comunicación. Es una estrategia comunicacional integral que se adapta a las transformaciones tecnológicas y a los nuevos vínculos con la ciudadanía en un contexto de crisis económica pero también política. Los técnicos comunican que: 
[...] a la depresión económica, proveniente de la actual situación, se han agregado las de orden climático registradas en la Provincia, tan extremas como no se recuerdan desde muchos años atrás. La ola de frío que invadió el invierno pasado el territorio de la Provincia y las heladas de consideración anotadas hasta ya avanzada la primavera, produjeron daños de importancia en los huertos frutales y hortícolas, en los campos de pastoreo y en las sementeras de cereales y papas; si se agrega a esto la sequía subsiguiente, proveniente de la falta casi absoluta de precipitaciones de importancia, unidas a una excesiva evaporación, consecuencia de las altas temperaturas y los vientos registrados durante el verano, se completa el cuadro desfavorable que ha presidido la producción agraria en el año que acaba de terminar (MOPPBA, 1943, p. 1).

La intensificación de la industria ganadera es un asunto que gana importancia, porque se pretenden adelantar producciones para satisfacer la demanda de carne. Se reorientan las acciones de los agricultores de la campaña bonaerense, con el aliento a la expansión ganadera, como el:

[...] método más rápido y seguro para salir de los malos tiempos actuales, ya sea acogiéndose a los préstamos especiales que otorga el Banco de la Nación Argentina o formando asociaciones de tipo de aparcería llamados a capitalización [...] en las que el habilitador entrega cierto número de cabezas de hacienda de cría al socio industrial, para repartir luego los productos en proporción convenida de antemano (MOPPBA, 1942, p. 2).

El único requisito para la transformación es la organización de la crianza, en forma "racional y producir los tipos que exige el mercado" (MOPPBA, 1942, p. 3).
El estudio de la tierra permite disponer un elemento vital para el desarrollo económico, enfatizando el "auxilio" del trabajador rural para lograr la eficacia de las actividades productivas. A través del asesoramiento, directivas y satisfacción de necesidades, se provee la interrupción del monocultivo y el fomento de la diversidad. Se establece que las formas para gestar canales de comunicación entre el gobernantes y gobernados se encuentran en la producción de la propaganda impresa en volantes, boletines, folletos, que sugieren reglamentaciones diversas para asegurar la existencia del sistema productivo (orientado al mercado agroexportador). Es útil mencionar la campaña de radiodifusión durante el último lustro, que mantiene un progreso sostenido en tanto difusor de mayor amplitud que los medios anteriores. En este sentido, se provee:

[...] desde la transmisora L S 11, Radio Provincia $[. .$.$] de acuerdo a un programa es-$ pecial que comprendía disertaciones breves sobre temas de actualidad para el agro, destinados al hogar rural o a contestar consultas sobre tópicos que son de competencia de la Repartición (MOPPBA, 1943, p. 5).

Se insiste en el lugar esencial ocupado por técnicos en contribuir a la solución de problemas regionales, quienes están capacitados para brindar estudios sofisticados y realización de información estadísticas. La labor de estaciones experimentales, como de los viveros oficiales, plazas, paseos públicos, parques, reforestando y embelleciendo las ciudades, aspecto que atraviesa al sujeto como ciudadano-trabajador-turista, son los aspectos vitales que refleja el Anuario como forma de disciplinamiento y para refundar el "control social". 


\section{Reflexiones finales}

La consolidación del Estado argentino es un proceso gradual, donde el biopoder disciplinar constituye ciudadanos a través de prácticas y lógicas concretas de gobierno. Los espacios geográficos se convierten en sociales porque son medidos y delimitados a través de las herramientas técnicas que vinculan el saber con el poder. También son interpelados como ámbitos productivos, por lo cual se convierte en una preocupación para el aparato estatal. Es parte de esa arquitectura de los vínculos de poder que definen un orden social sobre los que teoriza Michel Foucault, con el abordaje de las estructuras nacionales. Es un biopoder, un mecanismo que gestiona la vida - humana pero también animal y medioambiental -, mediante prácticas administrativas impersonales que posibilitan el crecimiento y la consolidación del capitalismo como sistema productivo.

El entramado institucional del Estado desarrolla "labores fundamentales para que los ciudadanos que viven en democracia tengan una vida razonable" (DU GAY, 2012, p. 20). Transformaciones que en la Argentina se producen en un contexto de excepcionalidad como es la primera ruptura del orden constitucional, con el golpe de Estado del 6 de septiembre de 1930. La ciudadanía política limitada se vincula con una ciudadanía "económica" que pretende canalizar las interacciones gobernantes-gobernados. Las actividades productivas cobran supremacía en el vínculo por el cual los gobernantes interpelan a los gobernados y la producción agropecuaria de la provincia más importante de la Argentina se convierte en una preocupación política.
El poder y el saber se potencian para promover políticas públicas que puedan interpretar a los sujetos como productores y al territorio como un ámbito productivo que construyen los actores sociales. Estas preocupaciones están presentes en el Anuario Rural de la Provincia de Buenos Aires, cuando la "productividad" supone una construcción compleja que trasciende la perspectiva económica. A través de la gubernamentalidad se interpretan las transformaciones que la crisis del liberalismo como pensamiento económico predominante, supone para el caso argentino la limitación de derechos políticos y la defensa de derechos económicos.

Las estructuras administrativas del Estado, en diálogo con otras instituciones, deben implementar un conjunto de prácticas para proteger a los productores rurales. Estas funciones sociales de la burocracia, promueven un abordaje que parte del reconocimiento de la diversidad de su objeto de estudio: un abordaje integral de los productores rurales. Se genera un vínculo entre el Estado y los productores, en donde los conocimientos técnicos actúan como una mediación. La preocupación por la productividad se "socializa" y la intervención estatal supone una resignificación de la "fe liberal" la clase política.

La socialización al interior de las instituciones estatales potencia el alcance de la gubernamentalidad y permite una rápida adaptación a las transformaciones del mercado mundial. La interdependencia entre los funcionarios que también son autores de los artículos que conforman el Anuario, lo consolida en un ámbito de difusión 
de conocimientos técnicos pero también en un ámbito de socialización entre expertos. El poder se potencia con el saber especializado pero también es un vínculo social que requiere de prácticas que actualicen las interacciones. El Anuario da cuenta de todas estas cuestiones y permite una compleja caracterización de los distintos roles que ocupan los funcionarios expertos en la estructura administrativa y en el vínculo de las instituciones con el resto de los actores que conforman el entramado social del mundo rural, heterogéneo y desigual.

\section{Abstract}

The historical process in Argentina 1930-1946 was caracterised by the interventionist state extension, a product of the Stock Market Crash of 1929, which put an end to the paradigm of outward-looking growth. It was a context of important changes in which the intervention went together with electoral fraud $y$ as it was developing in order to lead to a strict social control without refusing to the agricultural country. The implemented public policies questioned citizens as producers and the intervention adquiried a changing position in the productive practices as well as in the environment in which these interactions were added. The analysis of the Anuario Rural of Buenos Aires province, issued by the Ministry of Public Works, allowed us to understand the interventinist state process as an expression of the state expansion in its technical and bureaucratic aspects.

Keywords: State. Territory. Power

\section{Resumo}

O período histórico 1930-1946 na Argentina caracteriza-se pela ampliação do intervencionismo estatal, produto da crise econômica de 1929, que pôs fim ao modelo de crescimento econômico baseado no mercado internacional. Em um contexto de fortes mudanças, nas quais o intervencionismo foi reforçado pela prática de eleições fraudulentas, o controle social foi adquirido sem, contudo, renunciar a presença predominante da agropecuária na economia do país. As políticas públicas implementadas interpelaram os cidadãos, como no caso dos proprietários rurais, num intervencionismo que adquiriu um caráter transformador à produção agropecuária e ao meio ambiente. Para este estudo, a análise do Anuário Rural da Província de Buenos Aires, difundido pelo Ministério de Obras Públicas, permite compreender o processo intervencionista do Estado argentino em seus aspectos técnicos e administrativos.

Palavras-chave: Estado. Território. Poder.

\section{Notas}

1 Nace en 1885 y egresa como ingeniero agrónomo de la Facultad de Agronomía y Veterinaria de la Universidad de Buenos Aires en el año 1908. Además de ocupar el cargo de Director de Agricultura, Ganadería e Industrias (1936-1944), fue Vocal del Instituto Autárquico de Colonización (1936-1943), Vocal del Consejo de Vialidad (1936-1943) y Director de Agricultura e Industrias (1944).

2 El ingeniero agrónomo egresado de la Universidad de La Plata, pertenece al Consejo Superior de la misma siendo Consejero Titular. Es para 1934 Decano de la Facultad de Agronomía y Profesor Honorario de Agrología y Complementos de Mineralogía y Geología. 


\section{Referencias}

ARNAUDO, Aldo. Cincuenta años de política financiera argentina (1934-1983). Buenos Aires: El Ateneo, 1987.

AZARETTO, Roberto. Historia de las fuerzas conservadoras. Buenos Aires: CEAL, 1983.

BÉJAR, María Dolores. Otra vez la historia política: el conservadorismo bonaerense en los años treinta. Anuario del IEHS, Tandil, n. 1, p. 199-227, 1986.

CASTRO, Edgardo. El vocabulario de Michel Foucault: Un recorrido alfabético por sus temas, conceptos y autores. Universidad Nacional de Quilmes, 2004. Disponible en: <https:/ / psicologiaysociologia.files.wordpress. com/2011/08/castro-edgardo-el-vocabulario-de-michel-foucault.pdf $>$. Acceso en: 1 feb. 2016.

DU GAY, Paul. En elogio de la burocracia: Weber, organización, ética. Madrid: Siglo XXI, 2012.

FOUCAULT, Michel. Historia de la sexualidad: la voluntad de saber. México: Siglo XXI, 1999. v. 1.

Nacimiento de la biopolítica. Curso en el Collage de France (1978-1979). Buenos Aires: Fondo de Cultura Económica, 2012.

Seguridad, territorio, población: curso en el Collage de France: 1977-1978. Buenos Aires: Siglo XXI, 2007.

GIRBAL-BLACHA, Noemí María. Estado y economía en la Argentina de los años 30: La organización del régimen agrícola como antecedente del nacionalismo económico peronista. En: CONGRESO NACIONAL Y REGIONAL DE HISTORIA ARGENTINA, 10, 1999. Santa Rosa (La Pampa). Buenos Aires: ANH, 1999. p. 1-16.

Estado, chacareros y terratenientes (1916-1930). Buenos Aires: CEAL, 1998.
GIRBAL-BLACHA, Noemí María; OSPITAL, María; ZARRILLI, Adrián. Las miradas diversas del pasado. Las economías del interior ante la crisis de 1930. Buenos Aires: Edición Nacional, 2005.

GONZÁLEZ BOLLO, Hernán. La fábrica de las cifras oficiales del Estado argentino (1869-1947). Bernal: Universidad Nacional de Quilmes, 2014.

HALPERIN DONGHI, Tulio. La República imposible (1930-1945). Buenos Aires: Ariel Historia, 1995. (Biblioteca del Pensamiento Argentino V).

HEREDIA, Mariana. Cuando los economistas alcanzaron el poder (o cómo se gestó la confianza en los expertos). Buenos Aires: Siglo XXI, 2015.

LASCH, Christopher. La rebelión de las élites y la tradición a la democracia. Barcelona: Paidos, 1996.

MADDISON, Angus. Dos crisis: América y Asia 1929-1938 y 1973-1983. México: Fondo de Cultura Económica, 1988.

MANN, Michael. Fascistas. València: Publicacions de la Universitat de València, 2006.

Las fuentes del poder social: El desarrollo de las clases y los Estados nacionales, 1760-1914. Madrid: Alianza, 1997. v. II.

MCGEE DEUTSCH, Sandra. Las derechas: La extrema derecha en la Argentina, el Brasil y Chile, 1890-1939. Bernal: Editorial de la Universidad Nacional de Quilmes, 2005.

MIGDAL, Joel. Estados débiles. Estado fuertes. México: Fondo de Cultura Económica, 2011.

MOPPBA. MINISTERIO DE OBRAS PÚBLICAS DE LA PROVINCIA DE BUENOS AIRES.

Anuario Rural de la Provincia de Buenos Aires. 1938, 1940, 1941, 1942, 1943.

RAPOPORT, Mario. Historia económica, política y social de la Argentina (1880-2000). Buenos Aires: Ariel, 2006. 
ROCK, David. El radicalismo argentino. 1890-1930. Buenos Aires: Amorrortu Editores, 1977.

ROSE, Nikolas. Políticas de la vida: biomedicina, poder y subjetividad en el siglo XXI. La Plata: UNIPE, 2012.

ROUQUIÉ, Alain. Poder militar y sociedad politica en la Argentina. Buenos Aires: Emecé, 1981.

TCACH, Cesar. Sabattinismo y peronismo: partidos políticos en Córdoba 1943-1955. Buenos Aires: Sudamericana, 1991.

TRAVERSO, Enzo. La historia como campo de batalla: interpretar las violencias del siglo XX. Buenos Aires: Fondo de Cultura Económica, 2012.

ZABLUDOVSKY, Gina. Norbert Elias y los problemas actuales de la sociología. México: Fondo de Cultura Económica, 2007. 